\title{
CORE CORPORATE STRATEGIC CAPABILITIES: ROLE OF CORPORATE CAPABILITIES, INTEGRITY, INSTITUTIONS, AND IMPLICATIONS TOWARD SUSTAINABLE CORPORATE REPUTATION AND PERFORMANCE
}

\author{
Emmanuel J. Chao, Agder University, Norway
}

\begin{abstract}
Approaching markets that are at the bottom of the pyramid requires strategies which are different from those used at the top of the pyramid. Understanding the success in serving these markets requires examining strategic capabilities firms possess. Due to difference between strategic approaches in developed and developing markets, it is important to understand what makes strategic capabilities of multinationals in developing markets. Analysis of corporate capability is one of important mechanism in analysing strategic core. Assessing core strategic capabilities is not only a matter of assessing their ingredients but also assessing delivery of corporate objectives in a manner that is acceptable by society. If society dimensions are involved in core strategic composition, firms will ensure their reputation in carrying out their economic objectives.

This study intends to address the core strategic capability of multinationals in developing economy within constraints of corporate performance and reputation. Two constraints are involved because the core strategic capability has to ensure the sustainability of the two. The study view corporate capability to depend highly on corporate capabilities (innovation, leadership/managerial, financial and related competencies) as well as corporate integrity. Proposed study has predicted core strategic capability to be made of corporate capabilities, corporate integrity and their influence is mediated with institutions. Core strategic capabilities are also predicted to influence corporate reputation and performance.
\end{abstract}

Reference available upon request 